\title{
ENSEMBLE ARTIFACT DESIGN FOR CONTEXT SENSITIVE DECISION SUPPORT
}

\author{
Shah Jahan Miah \\ Information Systems Discipline, College of Business, \\ Footscray Park Campus, Victoria University, Melbourne, Australia \\ Email: shah.miah@vu.edu.au \\ John G. Gammack \\ College of Technological Innovation, \\ Zayed University, Abu Dhabi, U.A.E, \\ Email: John.Gammack@zu.ac.ae
}

\begin{abstract}
Although an improvement of design knowledge is an essential goal of design research, current design research predominantly focuses on knowledge concerning the IT artifact (tool) design process, rather than a more holistic understanding encompassing the dynamic usage contexts of a technological artifact. Conceptualising a design in context as an "ensemble artifact" (Sein et al., 2011) provides the basis for a more rigorous treatment. This paper describes an IS artifact design framework that has been generated from the development of several practitioner-oriented decision support systems (DSS) in which contextual aspects relevant to practitioners' decision making are considered as integral design themes. We describe five key dimensions of an ensemble artifact design and show their value in designing practitioner-oriented DSS. The features are user centredness, knowledge sharing, situation-specific customisation, reduced model orientation, and practice based secondary design abilities. It is argued that this understanding can contribute to design research knowledge more effectively both to develop dynamic DSS, and by its extensibility to other artifact designs.
\end{abstract}

Keywords: DSS, ensemble view, ensemble artifact, user-centredness, IS artifact, design science research.

\section{INTRODUCTION}

Currently design science knowledge in information systems (IS) distinguishes two different directions that are categorised variously in terms such as 'science of design' and 'design science', 'design research' and 'design science research' (e.g. Cross, 2001; Hevner, March, Park and Ram, 2004; Peffers et al., 2006; Winter, 2008). Winter's (2008) designation of '(IS) design research' vs '(IS) design science' reflects the essential difference in focus between specific artifact construction and a more general reflection towards theory development. Within design research also are differing emphases on the specific technical design, and on its evaluation in a user context. The influential paper by Orlikowksi and Iacono (2001), which restored to IS a focus on the IT artifact, suggested five metacategories covering its various conceptions within IS (namely: tool view, proxy view, ensemble view, computational view and nominal view). Of these the "ensemble view" concerns "the dynamic interactions between people and technology" (Orlikowski and Iacono, 2001, p.126), which includes technologies enmeshed or embedded in their wider systems of use. This category, however, constituted the smallest number of IS articles in their analysis of ISR (information system research) articles over 10 years, despite a strong socio-technical tradition and Orlikowski and Iacono's own observation (p.131) that all IT artifacts are inevitably embedded in a physical setting and (dynamic) discourse of ongoing use. They conclude that detailed practices of the use of IT artifacts must be integrated into 
theory. Yet since their paper little work in design science has focussed on this aspect. Using Winter's (2008) distinction, our aim in this paper is to develop a richer theoretical understanding of IS artifact design development together with its usage context, which is grounded in several previous case-studies of practitioner oriented decision support systems (DSS) development.

Arnott and Pervan (2005, 2012) have suggested that there is a need to improve the quality and relevance of research into DSS development and evaluation. In particular the clients and DSS artifact users are poorly identified in DSS scholarship (Arnott and Pervan, 2005), impacting relevance directly. The role of the artifact is one of the eight key issues they identify for the field (Arnott and Pervan, 2008) from the large sample of articles they analysed. Noting decision support's "design science heritage", they present statistics to indicate that both a micro focus on issues of artifact design (e.g. IT development), and a macro focus on (e.g organisational impact) are represented. It is unclear however, how many of the papers analysed considered both together. Their later analysis, however, which focussed explicitly on design science papers in DSS (Arnott and Pervan, 2012) found that the focus of $42.3 \%$ of papers was "the presentation and description of an artifact without any attempt to establish its worth, effectiveness or usefulness" (p.933).

Clearly issues of worth, effectiveness and usefulness will directly be referenced to professional practices in the field that the DSS addresses, and whilst some incidental understanding may emerge from traditional requirements gathering and analysis, it is unlikely that a full appreciation of changing requirements can be captured given the DSS developer is rarely an expert end user or domain practitioner. A different design approach is indicated.

The analysis of design research knowledge is mainly based on 1) conceptualization of the design research theory (Arnott and Pervan, 2012; McKay and Marshall, 2007; McKay, Marshall and Heath, 2008; Gregor and Jones, 2007); 2) theory building for enhancing our understanding of design science methodology (Hevner et al., 2004; Iivari, 2007;Venable, 2006) and 3) adaption of design research in IS (Purao and Storey, 2008; Botts, Schooley and Horan, 2008; Muntermann, 2009). The guidelines and methods of design research address the requirements of innovative design development, solution modelling or problem solving, and the evaluation of design (Hevner et al. 2004; Carlsson, 2006; McKay and Marshall, 2007). Many empirical studies have predominantly focused on different aspects of Hevner's et al. (2004) several guidelines, and suggested implications for better understanding of design research in IS development, but the original agenda of Hevner's guidelines fundamentally focuses on the technical artifact itself. The theoretical emphasis argued as necessary e.g. by Venable (2006) and by Gregor and Jones (2007), requires more explicit attention to the dynamic systems in which the artifact is embedded beyond the designed "solution" of a computer based IS referenced to some static business requirements.

As naturally embedded artifacts, DSS “represents a different philosophy of support, system scale, level of investment, and potential organisational impact. They can use quite different technologies and may support different managerial constituencies" (Arnott and Pervan, 2005 p. 68). Clark, Jones and Armstrong (2007) recognised the need to develop dynamic theoretical models for support systems development such as DSS and related technologies such as EIS (executive support systems), KMS (knowledge management systems) and business intelligence (BI). Their conceptual model (Clark et al., 2007) aimed not only to provide core and fundamental elements such as business process, organisational members, technology and organisational outcomes but also to capture the decision making environment and the use of these systems. Clearly this dynamic interaction argues for adopting an ensemble view.

The ensemble view is not new, but perhaps helps frame against the other meta-categories the older socio-technical tradition developed after WWII primarily by the Tavistock Institute (Mumford, 1983). This group identified a principle for participatory design in the context of artifact use namely "to 
increase the ability of the individual to participate in decision taking and through this to exercise a degree of control over the immediate work environment. Managers were advised to tell work groups what to do but not how to do it. The latter would come from the knowledge, experience and skill of each work group". (Mumford (n.d) see Mumford and Beekman (1994)). Long established in the UK, Scandinavia and Australia, many contemporary theorists also recognise the need, when developing IS applications, to include all aspects and how their processes and relationships are "entangled in practice" (e.g. Crowston, 2000, Orlikowski, 2009). This has led to various attempts to retheorise these concerns, particularly with respect to Design Science research.

Piramuthu and Shaw (2009) noted that traditional methods using pre-programmed routines help develop static DSS, however decision-making environment are not static and the fit is poor when a static tool is used in a dynamic environment. They suggest an adaptive framework with learning capabilities to incrementally update the knowledge base by monitoring for "stale" knowledge, but their perspective remains essentially a technological one.

Sein et al. (2011) proposed action design research (ADR) as an approach to design research that assumes building the artifact is "interwoven" with organisational deployment and evaluation. They note in passing that their ADR approach essentially articulates what others "serendipitously" do in practice, and their main focus is on detailing an appropriately relevant and rigorous research method for this. Theoretically adopting the ensemble view of Orlikowski and Iacono (2001) they claim to provide "methodological guidance for IS researchers who study the design of ensemble artifacts" (p.53). Goldkuhl $(2012,2013)$ however found Sein et al's transformation from an ensemble view to an ensemble artifact problematic, in part because it reifies a special class that implies non-ensemble artifacts exist. His conceptual paper looked more closely at the theoretical utility of the putative ensemble artifact by articulating more fully characteristics of the ensemble view only implicit in Orlikowski and Iacono's (2001) abstraction from particular sub-views. These include the essential embeddedness of the artifact in a dynamic social context, and the embodied social norms and structures built into the artifact's design. His work did not attempt any methodological prescription, but argues the need for better theory in this area ${ }^{1}$.

Socio-technical design is essentially a complex design process that includes interaction between the technical and social systems in order to encompass the totality of the design (Mumford, 1995). From a critical perspective, Carlsson (2006) argued that IS applications can be seen as socio-technical systems rather than just technology-centred artifact design and that design research should develop practical knowledge for the design and realisation of IS initiatives on this basis. The anticipation with this type of holistic analysis is that the context and relevance of IS should be more understood and explicitly accounted for. This motivates our general research question: How can we conceptualise IS artifact design to effectively accommodate its contextual usage? More specifically, we focus on designs for decision support, representing a class of IS that by nature essentially involves interaction between a designed artifact and a human decision maker using its outputs in a dynamic context.

The structured-case approach of Carroll and Swatman (2000) "enables the development of deep understanding of the complex interaction of people, processes and technology within organizations" (p.236) and builds theory from examination of professional practice. Importantly, this approach allows systematic and dynamic theory development through iteration and documented links to data. Informed by this, to capture user's situational realities and relevance to product, we use case studies of developed

${ }^{1}$ In the discussion we consider a response to this work by Sein's team (Purao et al., 2013). 
DSS application designs targeted to decision support problems (in particular where the design has to meet changing demands within a business context). From these we identify theoretical constructs, both from the literature and arising in practice that characterise components of a more general framework for rigorously building and evaluating DSS that are relevant directly to the practitioners' contexts.

The rest of this paper is organised in the following way. The next section describes the background of our problem in this study. Next, the methods used to develop the framework of artifact design are described, followed by the identified key components of our ensemble artifact. Finally, a discussion and summary are presented, along with proposed potential benefit to the knowledge in the field of design research for DSS development.

\section{BACKGROUND}

Our aim in this study is to extend the artifact design knowledge in design research. Design research “...seeks to create innovations that define the ideas, practices, technical capabilities, and products through which the analysis, design, implementation, management, and use of information systems can be effectively and efficiently accomplished" (Hevner et al., 2004, p.76). Winter (2008) suggested that although many contributions have been made to the justification of design, the typology of artifacts, or specific problem solutions, and rigour-related aspects are not yet sufficiently standardized to the design research community. March and Smith (1995) defined differentiation of constructs, models, methods, and instantiations as artifact types that have been well-accepted in IS design research (Hevner et al., 2004). Table 1 represents the meanings of the types of IS artifact.

\begin{tabular}{|l|l|}
\hline \multicolumn{1}{|c|}{ IS Artifact as } & \multicolumn{1}{c|}{ Definitions } \\
\hline Constructs & This type of artifact constitutes the language to specify problems and solutions \\
\hline Models & This type of artifact uses this language to represent problems and solutions \\
\hline Methods & $\begin{array}{l}\text { This type of artifact describes processes which provide guidance on how to solve } \\
\text { problems }\end{array}$ \\
\hline Instantiations & $\begin{array}{l}\text { This types of artifact explains problem-specific aggregates of constructs, models, } \\
\text { and methods }\end{array}$ \\
\hline
\end{tabular}

Table 1: Meanings of the artifact types (Adapted from March and Smith, 1995)

Improvement of the artifact design knowledge is an essential component of design research (Hevner et al., 2004; Hevner, 2007). This understanding can be helpful in guiding straightforward IT artifact design, if the main focus is in designing a new IT solution. Historically, constructs, methods and models are well covered in design research for DSS development (Arnott and Pervan, 2012). Our aim here is to examine particular instantiations of DSS artifacts as it is important to explain abstractable properties of technological DSS artifacts in order to provide applicable components "... for choosing desirable ends i.e., for normative actions" (Winter, 2008, pp. 471) and to extend these to design knowledge for their usage context.

The design science research school (what Carlsson (2007, p. 213) called the "IT design science research school") has however, a technological focus that explicitly excludes numerous soft factors. For example Cao et al. (2006) conceptualised design knowledge as a technology-centred design that concerns itself with technical innovation in the IT artifact design. However, McKay and Marshall (2007) and McKay et al. (2008) argued that this type of conceptualization excludes the surroundings of the design artifact. It shows a lack of understanding about IS artifacts design in an organizational 
context, where there are many human and social components. A design can be innovative in terms of how it can add value to decision makers/practitioner's desires, to improve practices or to achieve goals in its target problem space, but such features lie in the organisational or social realm, not the technological provisions.

Further to this, Iivari (2007) suggested that a design theory is not necessarily based on any scientifically validated knowledge; rather it could be based on any practitioner theory-in-use. This pragmatic concern also reinforces the generation of a collective understanding that may capture soft factors in design specially to better reflect practitioner-oriented surroundings into a design process.

McKay et al. (2008) explicitly viewed professional practices as a design dimension seeing identified responsibilities to clients or designers and broader social and environmental responsibilities as a design value. This view of design emphasises the "situatedness of the designer in a real-world context involving uncertainty, ambiguity and value conflict, and inevitably links design to the personal experiences, capabilities, knowledge and intuition of the designer" (p.9). It implies that practitioneroriented surroundings should have reflection built into a contextualised design process to better conceptualize and realize artifacts intended to address the target problem situation. This can assist capture of changing requirements and situational realities beyond the traditional requirements scope snapshot. However, involving professional practices as a design dimension has not been explored so far in existing DSS or design science literature.

To address this, findings from several different practitioner-oriented DSS development projects were revisited in this study. The development and evaluation details of a major project in rural industry (Miah, Kerr and Gammack, 2009; Miah, 2008), a second project in forestry pest management (Miah, Debuse, Kerr and Debuse, 2010) and third DSS development concerned in supplier selection issues (Miah, Ahsan and Msimangira, 2013). The previously published papers reported these DSS development projects separately highlighting their contribution within the targeted problem domains and describing their technical architectures. In addition, in earlier work following a tailorable and explicitly user-centred ("human-centred") design philosophy several DSS were built in the financial sector, to assess credit risk, to identify potential card fraud, and for various insurance applications (Gammack et al., 1992). Whilst these latter developments were mainly proof- of-concept prototypes at least one went on to commercialisation and this work also informed the present study.

In this paper, we focus on generalising the implications from the holistic design and evaluation activities in these various domains in considering professional practice as a design dimension. The findings were based on representative stakeholders' opinions solicited through focus group activities and system prototype evaluations. Focus groups have been recommended as a justified method in the design research paradigm (Tremblay, Hevner, Berndt, 2010), who described the adaptation of exploratory focus groups for artifact refinement and confirmatory focus groups for establishing the utility of the artifact in their healthcare design project. Arnott and Pervan (2012) also recommended their use given the endemic weakness of evaluation in DSS research and the narrow methodological base currently used for this. Generating such collective knowledge in the DSS artifact design may support development of flexible DSS applications by elevating the understanding of the end-users' work activities and the context in which they work. This embraces a user work centredness perspective i.e."understanding the relationship between people, technology, work requirements and organizational constraints in work settings, where people are actors in situations" (Iivari and Iivari, 2011, p. 131) who also considered that the extension of work centredness to activity-centredness could be a useful research challenge for future IS design. As an illustration of the work-oriented activity-centred method, the DSS artifact should take the system, users and the situation of use all together for an application development and their own context of use. Beyond these DSS design studies where an IT-based solutions is the key focus, we look at the DSS artifact seen from a collective innovation perspective as a socio-technical design, following Carlsson's (2006) suggestion that IS artifact design can be perceived as a socio- 
technical system. The adopted view is similar to the view of Mackrell, Kerr and von Hellens (2009), in which a socio-technical method was utilised to develop an agricultural DSS. Therefore our focus is on identifying relevant components of such an ensemble artifact using our previous research cases to enhance knowledge of socio-technical design research for designing specific DSS artifact. The "ensemble artifact" concept thus extends to addressing organisational and user context of use into useful IT artifact design.

\section{METHOD}

Gregor (2005) identifies five interrelated types of theory namely: theory for analysing; theory for explaining; theory for predicting; theory for explaining and predicting; and theory for design and action. Based on this classification of theory, we find the theory for explaining is most relevant to better describe our knowledge generated from the DSS development studies. It equally "could well be labelled as 'theory for understanding' as these theories often have an emphasis on showing others how the world may be viewed in a certain way, with the aim of bringing about an altered understanding of how things are or why they are as they are" (Gregor 2005, pp. 19). We adopt this view to explain our understanding on how things are and why they are considered important to enhance our understanding on artifact design.

As mentioned earlier Carroll and Swatman (2000) described a methodological framework called 'structured-case' in order to conduct IS theory-building research. This approach aimed help "building theory from field research" that examines professional practices. Carroll and Swatman (2000) described the approach for such field research that "enables the development of deep understanding of the complex interaction of people, processes and technology within organisations" (p.236) around three key elements: conceptual framework, research cycle and literature scrutiny for targeted theory building. According to this, the conceptual framework is initially produced from the research themes and existing knowledge gathered from literature. This helps form a basis for a research cycle conducted through four stages (plan, collect data, analyse, and reflect) similar to action research approaches, Finally literature scrutiny of targeted theory building compares the tentative findings with literature-established knowledge leading to review and revision of the understanding, through consolidating and examining conflicts between findings and literature (Carroll and Swatman, 2000). Based on their three element roadmap, we describe our research activities into three phases.

\section{Phase 1}

The decision making problems identified for the three different problem domains are similar in nature in particular where the solution designs for the decision support had to meet changing demands within the targeted business context. The first DSS design cycle was conducted in rural industries in which key decision makers were farmers and extension professionals in the context of the dairy farming business. The decision making, particularly in the dairy businesses in Queensland has faced rapid changes due to the effect of climate change, government regulations and farming method changes. This change has resulted in disuse of many DSS applications (McCowan, 2002; Cox, 1996; and Jakku et al., 2004). The responsible Government department such as the Department of Primary Industry and Fisheries (DPI) was looking for suitable DSS systems as well as an effective process that could improve management of the decision support application development activities (e.g. managers' roles are important to monitor the domain experts while involving DSS application development for the specific farmers group, in the contemporary DPI management context). End users such as farmers' systems on the other hand, needed to be accommodated to current contingencies. To address the changing needs for the target stakeholders in the industry (such as farmers, extension professionals and managers), an initial solution was designed to reflect on the appropriate interaction in which farmers can achieve their situation-specific decision support obtaining expertise and knowledge from dairy extension 
professionals. A rule based (if-then-else) decision approach which is tailorable to farmer's rules of thumb (practice based knowledge), was used for the end user system. The solution was evaluated through focus groups. The following protocols (see table 2 below) were used:

\begin{tabular}{|l|l|}
\hline \multicolumn{1}{|c|}{ Steps } & \multicolumn{1}{c|}{ Descriptions } \\
\hline Step 1 & Introduction to the project and its goals \\
\hline Step 2 & General information of the developed method given to all participants \\
\hline Step 3 & Prototype method is demonstrated by running industry relevant examples \\
\hline Step 4 & $\begin{array}{l}\text { Participants are asked specific questions about the method and if there were areas } \\
\text { they were unsure of }\end{array}$ \\
\hline Step 5 & A time interval is offered to the participants to use the method \\
\hline Step 6 & Have discussion and capture participants views on the key functionalities \\
\hline Step 7 & $\begin{array}{l}\text { Participants are requested to provide detailed information about their understanding } \\
\text { and views of the method }\end{array}$ \\
\hline Step 8 & $\begin{array}{l}\text { At the end of the focus group meeting, the participants are thanked for their time and } \\
\text { effort }\end{array}$ \\
\hline
\end{tabular}

Table 2: Evaluation protocols used for the DSS development studies

\section{Phase 2}

The process developed in phase 1 was modified to adjust with work environment of forestry pest management. In this problem space, most of the previous DSS processes use knowledge from various domains in providing support for specific decision making problems. However, very few studies have identified the requirements of developing a combined DSS process in which relevant practitioners can contribute and share knowledge for effective decision making (Miah et al., 2010). The model-based DSS such as DYMEX (Maywald et al., 2004), a very popular DSS, are unformed in terms of the involvement of practitioners in system development (Miah et al. 2010). At the same time, pest management knowledge is continually evolving, and DSS should reflect this by incorporating new knowledge to determine the most appropriate practice. The two key stakeholder groups, scientists and foresters, were identified within this problem domain. To address the issue here, the proposed modified DSS process was mainly to enable the interaction between scientists and practitioners for better knowledge incorporation. To enhance collaboration in their work environment we invented the key system features in which end users (such as foresters) can adjust their business factors by adding/modifying/deleting into the system, under a secondary design principle ${ }^{2}$ (Germonprez, Hovorka and Gal, 2011). Users draw their particular problem scenario to find out particular scientific knowledge

2 Secondary design principle can be seen as an ongoing activity for tailoring IS applications by the end users so that it fits within their context. Germonprez et al. (2011) described the secondary design view where "people are active, aware, and intentional participants in an ongoing process of embodied interactions involving technological and social dualities" (p.663) 
support to improve or minimise the potential risks. Scientists can add scientific knowledge and stepby-step suggestions to improve the foresters' specific practices. This use of inputs from end users helped to implement better interactions in IS solution artifact design. The domain specific details provided us to allocate features of knowledge sharing in the relevant decision support specific to situation and its possible customisation required to adjust the changes demands. Our findings from the third project in a supplier selection problem in the supply chain management domain suggested similar demands as purchase officers need to have knowledge sharing with their managers in order to make decisions on which suppliers will be suitable to purchase specific products (Miah et al., 2013). The selection parameters change due to the market or price/service terms and conditions changes. As a value adds to the solution design, we employed the user-centred and work-related features as value adding provisions to DSS solution artifact, as part of the innovation. Table 3 illustrates some comments captured during the system evaluation using same protocols.

\begin{tabular}{|l}
\hline Dairy industry stakeholders \\
\hline Farmers \\
"Simple means of organising thoughts into a logical framework ... Ability \\
to modify, and suited to changing environment in addressing specific \\
issues on a industrial farm" \\
\hline Extension officer \\
"The system seems overall simple and straightforward in data entry to me, \\
however, it needs to incorporate the biological settings to improve the \\
ability of the system which could be done by a knowledgeable user". \\
(Research diary: 15 February 2008) \\
DPI management \\
"This is a nice little piece of software where we may control the decision \\
support tools development activities which are very important from the \\
management point of view".( Research diary: 22 August, 2007) \\
\hline Forestry industry stakeholders \\
Forestry Health Scientist \\
"because for the DYMEX [a popular DSS in forestry] the leaf beetles will only be a \\
proportion of the damage in some years. They're very hard to find, let alone see the damage. \\
So I think yeah, like Mr_X_. was saying, the generic model is probably a good one to start \\
with, and we know that we've got the industry support for that"
\end{tabular}

Table 3: Example focus group data to demonstrate the practitioners' orientation during the design research

\section{Phase 3}

To refine our practical understanding, we analyse our findings through DSS literature to justify its value in DSS development. Research work by Arnott and Pervan (2008; 2006; 2005) consistently outlined the gap of user's involvement as mentioned earlier. We aimed at interpretive understanding to learn about target decision making aspects of practitioners (in both cases) within their practical environment. From phases 1 and 2 we found that a socio technical design is important for industry practitioners' DSS design. To enhance tailorability, knowledge sharing and work-activity centredness, the design features were identified to address the vital issues such as practitioner context of use and knowledge sharing and collaboration issues. The findings led to identify the relevant components for a framework of DSS artifact design. 


\section{COMPONENTS OF THE "ENSEMBLE" ARTIFACT}

The concept of IT artifact is problematic in design science and in IS generally (Alter 2003). For present purposes we refer to the "ensemble artifact" characterised in the Action Design Research approach of Sein et al. (2011) to locate our work, albeit with some qualification as we discuss later. We also recognise the numerous particular formulations that offer good analysis, coherent arguments and constructive suggestions but which have perhaps hampered a standardised conceptual coherence. Three examples may illustrate: the communication tool view of IT artifacts (Goldkuhl, 2012); the semizoic artifacts proposed by Gregor and Iivari (2007) which recognises the spectrum of design from the formulaic to its changing and emergent aspects, and Alter's (2003, 2013) " work systems in organisations" vision (which makes deference to the broad predecessor sociotechnical tradition) and where the term "IT artifact" is understood (preferably) as the entire IT-reliant work system. Whilst not identical, all can be seen as useful integrations around a similar problematic and embracing an ensemble view of design. Our intention here is not to add a competing formulation, but to identify theoretical components relevant to design that explicitly follows an ensemble view and which can become operationalized in specific design contexts.

We analysed relevant practical findings of DSS solution developments to find out key components of DSS artifact design in practical contexts of design. The findings suggest five key components that are of value in designing practitioner-oriented DSS design. The components are user centredness, knowledge sharing, situation-specific customisation, reduced model orientation, and practice based secondary design abilities. Our view is similar to the view of McKay et al. (2008) in that it suggests the potential use of a human centred perspective in design to expand contextual knowledge in a design artifact. Based on a theoretical analysis McKay et al. (2008) identify various viewpoints of design such as design as product, design as process or action, design as intention, design as planning including modelling, representation and method, design as communication, design as user experience, design as a value, design as professional practice and design as service. Our study is different in that our case analysis is focused on the design perspectives around users and their situation of use to illustrate some key components of design in particular to DSS design. The following sections describe the identified components:

\section{User-centredness of artifact}

Iivari and Iivari (2011) suggested four aspects of user-centredness, namely, a focus on the system user; a focus on user work-centredness; a focus on user involvement; and a focus on system personalisation. We found that DSS design requires end-user inputs to outline the support processes required for artifact design. At the same time, DSS analysts need to understand end user desires and decision support requirements. The DSS literature supports this perspective for example in agricultural DSS development contexts (Cox, 1996; McCown, 2002): McCown (2002) particularly noting a lack of fit between knowledge embodied in the system and the dynamic industry context in which business operates. Contemporary design research suggested that design should focus on design by enhancing user centredness through encouraging or empowering them in the design process; this can be defined as a focus on the user work centredness (Iivari and Iivari, 2011), an argument long advocated by Alter and others (e.g. Alter, 2013).

Although many dimensions of user centredness such as user involvement or system personalisation can have application in DSS design, work centredness appears to be most relevant to practitioner-oriented DSS design, since most practitioners would expect their work environment reflected within the solution design. In Alter's Work System Theory (2013) he notes implementation means in the organisation, not the algorithm, and modelling provision for workarounds, bricolage and emergent change is required. 
Designing (decision) environments around work-referenced "design spaces" provides for this secondary design capability.

\section{Knowledge sharedness of artifact}

In the scenarios of DSS developments, we found that DSS should have features for knowledge sharing between user groups, specially for incorporating new knowledge to determine appropriate or effective practices and for relevant decision support aids. Specifically, the dairy DSS includes knowledgesharing provisions for the interaction of farmers and extension professionals (Miah et al., 2009; Miah, 2009), whilst the forest pest example represents a process for scientists and practitioners to incorporate new scientific knowledge into practice. The practical findings show way to map both features for practitioners and domain expert (such as DSS analysts). This perspective has been reflected in the DSS literature, particularly in medical informatics. For example, Achour et al. (2001) highlighted the importance of knowledge sharing feature in Clinical DSS design for different user groups such as doctors and other health professionals to determine appropriate treatments. In design research, Hevner et al. (2004) suggested that design artifact must address the complex interactions among subcomponents of the problem and its solution. In our case, the relevant interaction in terms of knowledge-sharing is seen as a key component of decision support. Extensible knowledge representations such as contextual graphs that allow for updating without re-engineering may be used to add dynamism to a DSS (Sherwell et al., 2005).

\section{Situation specific customisation of artifact}

Situation specific customisation in DSS development for rural business applications has been identified within the agricultural DSS literature. Kerr (2004), McCown, (2002), and Hayman and Easdown (2002) noted that most agricultural DSS are not suitable for rapidly changing situations such as industry regulations and marketing policies that impact directly on decision making, since they lack customisable features to such changes. The DSS development projects demonstrated a clear requirement of situation-specific customisation. Practitioner-oriented DSS should have some dynamic provisions for adding or modifying decision making parameters to meet changing requirements without requiring intermediate design stages. In design research, Germonprez et al. (2011) described a case of behaviour design research in that a secondary view is proposed to consider users as designers in their own right during the ongoing creation and recreation of application to adjust with problem space. This user-as designer philosophy was also more fully articulated and implemented in the DSS developed by Gammack et al. (1992).

\section{Reduced model orientation of artifact}

Prior DSS development studies utilised simulation and survey data for DSS model development (Kerr and Winklhofer, 2006; Karmakar, Lague, Agnew and Landry 2007). Most such models become obsolete quickly due to the changes of user environment and business situations. For example, if new knowledge is to be incorporated, DSS may suffer from knowledge transferring issues such as advising difficulties between farmers and extension officers (McCown, 2002; Kerr, 2004; Carberry et al., 2002). Outcomes from Model based DSS also vary site to site, season to season and agreed practice to practice. In design research, the situation appears due to lack of understanding about IS artifacts design in an organizational context, where many behavioural factors, involving human and social components are to be acknowledged. In other words, a design must also be innovative in terms of how it can add value to decision makers/practitioner's practical desires within their own context. To recognise the need, when developing a DSS artifact, we should have a reduced model orientation to targeted artifact design so all aspects can be addressed through how the processes and relationships should be "entangled in practice" for the targeted user. 


\section{Practice based secondary design facilities of artifact}

One of the issues in previous DSS development is the lack in practical knowledge for DSS design, as most models are designed as a result of research or theory building or problem solving (Arnott and Parven, 2012; Jakku et al., 2004; McCown, 2002; Cox, 1996). Attempts to train or encourage end users to develop DSS have traditionally failed and for complex systems this approach is undesirable (Power, 2010). But a technical focus on the developed DSS does not consider domain-centric practical realities. We found it is important to accommodate practitioner's practical consequences into decision-making context. For instance, in dairy DSS, the study articulated practical decision making rules of thumb that are significant for DSS design. In design research this reality can also be informed through the idea of secondary design Germonprez et al. (2011) in that the design perspective recognizes user's behaviours and contexts change over time and when IS artifacts are engaged and customised by users in their work or problem space. An architecture that allows both end user customisation and more rigorous and informed tailoring through a secondary design facility helps address organisational dynamism, and was implemented in the systems described by Gammack (2002) and Miah (2009).

\section{DISCUSSION AND CONCLUSIONS}

For DSS design, traditional DSS development methods have several limitations in supporting businesses, including conceptual mismatches, static models and inflexibility. This has resulted in poor uptake or disuse. The study considered the contextual knowledge around (DSS) artifact design in which an 'ensemble' artifact design view is adopted to represent entanglement of artifact, user and their situation of use. In the specific DSS development context the approach is considered to address more practically the utility and ongoing relevance of a design. Our approach integrates the simple IT artifact design knowledge with explicit consideration of use in a practical context by identifying five key components for ensemble artifact design. The key components of framework are user centredness, knowledge sharedness, situation-specific customisation, reduced model orientation, and practice based secondary design abilities, combined in order to enhance the influence of professional practices as an explicit design dimension in artifact development. These components emerged from a structured-case approach based on a range of decision support systems (DSS) development contexts, in which abstractions and reflections on key findings from potential stakeholders formed the basis of a grounded understanding. These five components capture central aspects of an artifact's 'interwoven' characteristics and help identify requirements of interactions between people and technology. Methodologically the action design research approach of Sein et al. (2011) is naturally compatible with this, and indeed in our earlier individual studies, the iterative, evolutionary and joint application development and evaluation processes that were followed ensured continual referencing to the usage context (see Miah et al. 2009, Miah, 2009).

The established practices in the tool focussed aspects of IT artifact design, although concerned with the design prior to implementation and use and cognizant of both technical and behavioural aspects, leave concerns around users' situations and related practicalities un-addressed in the context of their everyday or professional activities. Our framework addressed this gap by enabling user-centredness as an important component of DSS artifact design supported through specific user-centred principles (Iivari and Iivari, 2011) and making provision for secondary design. Regarding knowledge sharing, a common issue across developments was the dynamism in the organisational context, where unanticipated factors required design adaptations. In the agricultural applications for example, changing market demands, new business rules and scientific findings known to the government must be shared with the (farmers) who themselves have local knowledge that requires contextual interpretation and a customisation capability. To facilitate dynamism the model orientation is reduced since over-fixing a technical solution is inflexible, obsolescent, and may become irrelevant with only a minor change in 
organisational context. Such changes can be managed though by designing for tailorability using secondary design approaches.

We believe these five elements are all essentially understood, conceptualised and operationalized variously throughout the IS literature, and implementing them in specific designs using the ensemble view is practicable. Theoretically, however, we have largely refrained from using the term "ensemble artifact" because although we broadly agree with Sein's et al. (2011) description a deeper problem is the field's various conceptualisations of the IT artifact and whether the term is generally useful in building design science knowledge. We therefore conclude our discussion with a brief consideration of this point.

Alter (2003) argued that the notion of "IT artifact... is too unclear to serve as a basic concept for defining the IS field" (p.496) and Winter (2008) suggested that the typology of artifacts to specific problem solutions are not yet sufficiently standardized to the IS design research community. Goldkuhl's (2012) penetrating criticisms of (Sein et al.'s) proposed "ensemble artifact" were "rebutted" by that team (Purao et al., 2013) by claiming that the short hand term (derived from but not to be compared to the ensemble view) "emphasizes the key characteristics that exhort IS researchers to adopt a view of all IT artifacts as ensemble artifacts" (p.76). This would be theoretically vacuous if it mapped to Orlikowski and Iacono's set of views, but these authors disclaim any direct lineage, arguing that their contrast is with the dominant "tool view" in design research, which is our own position. More usefully they rephrase the incisive criticism " ..."aren't all artifacts ensemble artifacts" (answer =yes) as "..."are all artifacts built as ensembles?" (answer = no)" (p.78). This does not end the argument of course, but highlights the ongoing problems in our field of settling on any standard set of basic ontological categories.

Our work has been on DSS and we do not make a claim to greater generality here. Since, however, DSS exemplifies an essentially embedded, interwoven and dynamic application area, the framework suggests a generalisability to other contextualised IS artifacts. Our proposed framework of holistic DSS artifact design is supported through the incorporation of both user-centred and secondary design principles that has not previously been dominant within the DSS development context. This may lead to wider transformation in DSS development processes and to relevant knowledge for design science research more widely.

\section{REFERENCES}

Achour, S.L., Dojat, M., Rieux, C., Bierling, P. and Lepage, E. (2001). A UMLS based Knowledge Acquisition Tool for Rule based Clinical Decision Support System Development, Journal of the American Medical Informatics Association, 8, 351-360

Alter, S. (2003). Sidestepping the IT artifact, scrapping the IS silo, and laying claim to systems in organizations. Communications of the Association for Information Systems, 12(30), 494-526.

Alter, S. (2013). Work Systems Theory: Overview of Core Concepts, Extensions, and Challenges for the Future, Journal of the Association for Information Systems, 14 (2), 72-121

Arnott, D. (2006). Cognitive biases and decision support systems development: a design science approach, Information Systems Journal, 16, 55-78

Arnott, D. and Pervan, G. (2008). Eight key issues for the decision support systems discipline, Decision Support Systems, 44(3), 657-672

Arnott, D. and Pervan, G. (2012). Design Science in Decision Support Systems Research: An Assessment using the Hevner, March, Park, and Ram Guidelines, Journal of the Association for Information Systems, 13 (11), 923-949. 
Botts, N., Schooley, B. and Horan, T.A. (2008). Learning object development and repository design for digital government instruction, The Proceedings of the 41st Hawaii International Conference on System Sciences, USA, 1-10.

Cao, J., Crews, J.M. Lin, M. Deokar, A.V. Burgoon, J.K. Nunamaker Jr. J. (2006). Interactions Between System Evaluation and Theory Testing: A Demonstration of the Power of a Multifaceted Approach to Information Systems Research Journal of Management Information Systems, 22 (4), 207-235.

Carberry, P.S., Hochman, R.L., McCown, R.L., Dalglish, N.P., Foale, M.A., Poulton, P.L., Hargreaves, J.N.G., Hargreaves, D.M.G., Cawthray, S., Hillcoat, N. and Robertson, M.J. (2002) The FARMSCAPE approach to decision support: farmers', advisers', researchers' monitoring, simulation, communication and performance evaluation, Agricultural Systems, 74 (1), 141-177

Carlsson, Sven A. (2006). Design Science Research in Information Systems: A Critical Realist Perspective, The Proceedings of the Australasian Conference on Information systems (ACIS 2006). Paper 40. http://aisel.aisnet.org/acis2006/40 accessed 2/11/13

Carlsson, S.A. (2007). Developing Knowledge Through IS Design Science Research: For Whom, What Type of Knowledge, and How, Scandinavian Journal of Information Systems, Vol. 9(2), pp.75-86

Carroll, J.M. and Swatman, P.A. (2000). Structured-case: a methodological framework for building theory in information systems research, European Journal of Information Systems, 9, 235-242

Clark, T.D., Jones, M.C., and Armstrong, C.P. (2007). The Dynamic Structure of Management Support Systems: Theory Development, Research Focus, and Direction, MIS Quarterly, 31 (3), 579-615

Cox, P.G. (1996). Some issues in the design of Agricultural Decision Support Systems, Agricultural Systems, 52, 355-381

Cross, N. (2001). Designerly ways of knowing: design discipline versus design science, Design Issues, 17(3), 49-55

Crowston, K. (2000). Processes as theory in information systems research. In R. L. Baskerville, J. Stage \& J. I. DeGross (Eds.), Organizational and Social Perspectives on Information Technology Proceedings of the IFIP TC8 WG8.2 International Working Conference on the Social and Organizational Perspective on Research and Practice in Information Technology, Kluwer Academic, June 9-11, Arlborg, Denmark, 149-164.

Gammack, J. G. (2002). Constructive Design Environments: Implementing End-User Systems Development. In T. Barrier (Ed.), Human Computer Interaction Development \& Management, Hershey, PA: IRM Press, 153-173

Gammack, J. G., Fogarty, T. C., Battle, S. A., Ireson, N. S., \& Cui, J. (1992). Human-centred decision support: The IDIOMS system. AI \& Society, 6(4), 345-366.

Germonprez, M., Hovorka, D. and Gal, U. (2011).Secondary Design: A Case of Behavioral Design Science research, Journal of the Association for Information Systems, 12 (10), 662-683

Gregor, S. (2005). The Nature of the Theory in Information Systems, MIS Quarterly, 30 (3), 611-642

Gregor, S. and Iivari, J. (2007). Designing for mutability in Information Systems, In D. Hart and S. Gregor (Eds.). Information Systems Foundations: Theory, Representation and Reality, Australian National University E-Press, Canberra. (URL: http://epress.anu.edu.au/info_systems02_citation.html)

Gregor, S. and Jones, D. (2007). The anatomy of a design theory, Journal of the Association for Information Systems, 8, 321-335. 
Goldkuhl, G. (2012). What is an ensemble artefact?. International workshop on IT Artefact Design \& Workpractice Intervention, 10 June, 2012, Barcelona http://liu.divaportal.org/smash/record.jsf?pid=diva2:583573

Goldkuhl, G. (2013). From ensemble view to ensemble artefact - an inquiry on conceptualisations of the IT artefact, Systems, Signs \& Actions , Vol 7 (1), p 49-72

Hayman, P.T. and Easdown, W.J. (2002). An ecology of a DSS: reflections on managing wheat crops in the North-eastern Australian grains region with WHEATMAN, Agricultural Systems, 74, 5777

Hevner, A., March, S., Park, J., and Ram, S. (2004). Design Science in Information Systems Research, MIS Quarterly, 28(1), 75-105

Hevner, A. (2007). A Three Cycle View of Design Science Research, Scandinavian Journal of Information Systems, 19 (2), 87-92.

Iivari, J. (2007). A paradigmatic analysis of information systems as a design science, Scandinavian Journal of Information Systems, 19 (2), 39-64

Iivari, J. and Iivari, N. (2011). Varieties of user-centredness: an analysis of four systems development methods, Information Systems Journal, 21, 125-153

Jakku, E. Thorburn, P. and Gambley, C. (2004). Decision support systems for farm management: a theoretical framework from the sociology of science and technology, In the proceedings of the 4th International Crop Science Congress (URL: http://www.cropscience.org.au/icsc2004/poster/4/1/1/1219_jakkues.htm Retrieved on 20 January, 2012)

Karmakar, S., Lague, C., Agnew, J. and Landry, H. (2007). Integrated decision support system (DSS) for manure management: A review and perspective, Computers and Electronics in Agriculture, 57, 190-201

Kerr, D. and Winklhofer, H. (2006). The effect of rapid rural industry changes on the development of a decision support system for dairy farmers in Australia, Computers and Electronics in Agriculture, 50, 61-69

Kerr, D.V. (2004). Factors influencing the development and adoption of knowledge based decision support systems for small, owner operated rural businesses, Artificial Intelligence Review, 22 (2), 127-147

Maywald, G.F., Sutherst, R.W. and Kriticos, D.J. (2004). DYMEX Professional: Modelling Natural Systems, Version 2.0, Hearne Scientific Publishing, Melbourne.

Mackrell, D., Kerr, D.V. and von Hellens, L. (2009). A qualitative case study of the adoption and use of an agricultural decision support system in the Australian cotton industry: the socio-technical view, Decision Support Systems, 47, 143-153.

March, S.T., and Smith, G. (1995). Design and natural science research on information technology, Decision Support Systems 15(4), 251-266

McCown, R.L. (2002). Changing systems for supporting farmers decisions: problems, paradigms, and prospects, Agricultural Systems (74), 179 -220

McKay, J. and Marshall, P. (2007). Science, design and design science: seeking clarity to more design science forward to information systems, In the proceedings of the 18th Australasian Conference on Information Systems, Sydney, 1-11

McKay, J. Marshall, P. and Heath, G. (2008). An Exploration of the Concept of Design in Information Systems, In the proceedings of The 4th Biennial ANU Workshop on Information Systems Foundations, Information Systems Workshop, Australian National University, Canberra, Australia. 
Miah, S.J. (2008). An ontology based design environment for rural decision support, Unpublished PhD thesis, Griffith University, Australia.

Miah, S.J. (2009). End User as Application Developer for Decision Support, In the Proceedings of the Fifteenth American Conference on Information Systems, Aug 6-9 2009, San Francisco, California, USA, 142

Miah, S.J., Kerr, D. and Gammack, J. (2009). A methodology to allow rural extension professionals to build target-specific expert systems for Australian rural business operators, Expert Systems with Applications (36), 735-744.

Miah, S.J., Debuse, J., Kerr, D. and Debuse, V. (2010). A Practitioner-Oriented Decision Support Process for Forestry Pest Management, In the proceedings of the 21st Australasian Conference on Information Systems, 1-3 Dec 2010, Brisbane, Australia, pp. 1-10

Miah, S.J, Ahsan, K. and Msimangira, K.A.B. (2013). An Approach of Purchasing Decision Support in Healthcare Supply Chain Management, Operations and Supply Chain Management: An International Journal, 6 (2), 43 - 53.

Muntermann, J. (2009). Towards ubiquitous information supply for individual investors: A decision support system design, Decision Support Systems, 47, 82-92

Mumford, E. (1995). Effective Requirements Analysis And Systems Design: The ETHICS Method, Macmillan, London.

Mumford E. (1983). Designing Human Systems for New Technology - The ETHICS Method, Manchester Business School.

Mumford, E. and Beekman, G. J. (1994). Tools for change and progress: A socio-technical approach to business process re-engineering. Leiden: CSG quote is summary by Mumford at http://www.enid.u-net.com/Sociotech.htm 2/11/13

Orlikowski, W. (1992). The duality of technology: rethinking the concept of technology in organisations, Organisation Science, 3 (3), 398-427

Orlikowski, W. J. (2009). The sociomateriality of organisational life: considering technology in management research, Cambridge Journal of Economics, 34 125-141

Orlikowski W J, and Iacono C. S. (2001). Desperately seeking the "IT" in IT research - a call to theorizing the IT artifact, Information Systems Research, 12 (2), 121-134

Purao, S and Storey, V.C. (2008) Evaluating the adoption potential of design science efforts, The case of APSARA, Decision Support Systems, 44, 369-381

Purao, S., Henfridsson, O., Rossi, M.; and Sein, M. (2013). Ensemble Artifacts: From Viewing to Designing in Action Design Research, Systems, Signs \& Actions, An International Journal on Information Technology, Action, Communication and Workpractices, 7 (1), 73-81.

Piramuthu, S. and Shaw, M.J. (2009). Learning-enhanced adaptive DSS: a design Science perspective, Information Technology Management, 10, 41-54

Power D (2010). What are concerns about end-user DSS development? Available: http://dssresources.com/faq/index.php?action=artikel\&id=208

Steinbauer, M.J., Kriticos, D.J., Lukacs, Z., Clarke, and A.R. (2004). Modelling a forest lepidopteran: phonological plasticity determines voltinism which influences population dynamics, Forest Ecology and Management, 198, 117-131

Sherwell, B. W., Gonzalez, A. J. and Nguyen, J. (2005). Contextual Implementation of Human Problem -solving Knowledge in a Real-World Decision Support System. Proceedings of the Conference on Behavior Representation in Modeling and Simulation, Los Angeles, CA, May. http://cc.ist.psu.edu/BRIMS2013/archives/2005/papers/05-BRIMS-025.pdf 
Sein M, Henfridsson O, Purao S, Rossi M, and Lindgren R. (2011). Action design research, MIS Quarterly, 35 (1), 37-56

Tremblay, M. C., Hevner, A. and Berndt, D. J. (2010). Focus Groups for Artifact Refinement and Evaluation in Design Research, Communications of the Association for Information Systems, 26, 599-618.

Venable, J.R. (2006). The Role of Theory and Theorising in Design Science Research, in Chatterjee, S. and Hevner, A. (Eds), First International Conference on Design Science Research in Information Systems and Technology, Feb 24 2006. Claremont, CA: Claremont Graduate University.

Winter, R. (2008). Design science research in Europe, Guest editorial, European Journal of Information Systems, 17, 470-475. 